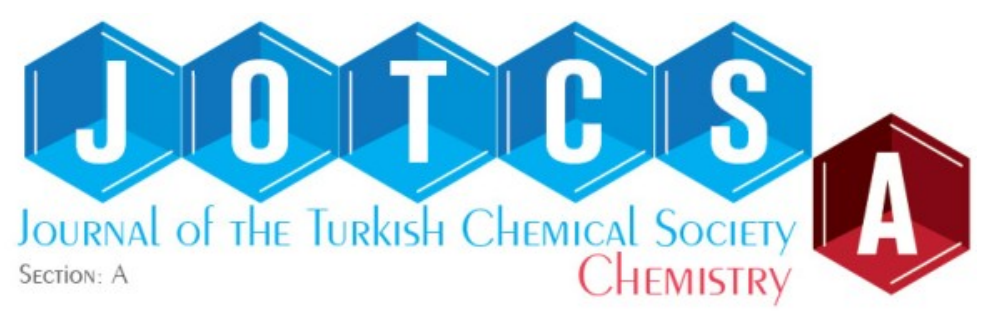

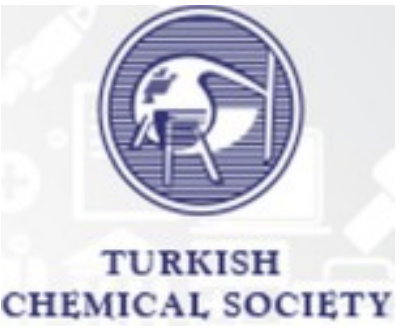

\title{
Synthesis, Characterization, and Use of Lanthanide Chelate of $\beta$ - Diketonate Based Ligand as a Luminescent Biolabel
}

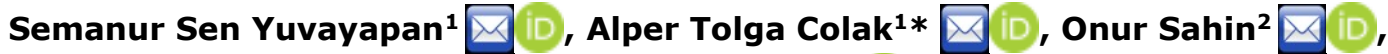 \\ and Cumali Celik 3 iD \\ ${ }^{1}$ Department of Chemistry, Faculty of Arts and Sciences, Dumlupinar University, Kutahya, Turkey \\ ${ }^{2}$ Department of Occupational Health \& Safety, Faculty of Health Sciences, Sinop University, Sinop, Turkey \\ ${ }^{3}$ Department of Property Protection and Security, Yalova Vocational School, Yalova University, Yalova, \\ Turkey
}

\begin{abstract}
In this study, we aimed to synthesize a $\beta$-diketonate-based ligand and its Eu(III) complex which are used for luminescent biolabel. For this purpose, we chose acetophenone as the starting material which contains methyl group at the alpha position of the ketone group. Firstly, we obtained $4,4,5,5,6,6,7,7$-octafluoro-3,8-dihydroxy-1,10-diphenyldeca-2,8-diene-1,10-dione ( $\left.{ }_{2} \mathrm{ODIT}\right)$ ligand in a reaction between acetophenone and diethyloctafluoroadipate with Claisen condensation. This ligand was characterized by ${ }^{1} \mathrm{H}-\mathrm{NMR},{ }^{13} \mathrm{C}-\mathrm{NMR}$, and mass spectral analyses. We obtained a single crystal $\mathrm{H}_{2} \mathrm{ODIT}$ as characterized by X-ray analysis. At the second step, in order to bind $\mathrm{H}_{2}$ ODIT to the antibody, it is reacted with chlorosulfonic acid. As a result of this reaction, the functional group of $-\mathrm{ClSO}_{2}$ was bound to the structure. The structure of $\mathrm{H}_{2}$ CODIT was characterized by NMR and mass spectral analysis. In the third step, to understand the usability of the ligand as a biolabel, the complex compound was synthesized with $\mathrm{EuCl}_{3}$. The complex compound was excited with UV light at $306 \mathrm{~nm}$ wavelength, specific hypersensitive ${ }^{5} D_{0} \rightarrow{ }^{7} F_{2}$ phosphorescence electronic transition of the Eu(III) was observed which proved that the luminescent $\mathrm{H}_{2}$ CODIT molecule can work as a biolabel.
\end{abstract}

Keywords: Beta-diketonate, Claisen condensation, europium(III) complex, keto-enol tautomerism, luminescence, biolabel.

Submitted: June 09, 2021. Accepted: July 18, 2021.

Cite this: Sen Yuvayapan S, Colak AT, Sahin O, Celik C. Synthesis, Characterization, and Use of Lanthanide Chelate of $\beta$-Diketonate Based Ligand as a Luminescent Biolabel. JOTCSA. 2021;8(3):835-50.

DOI: https://doi.org/10.18596/jotcsa.949970.

*Corresponding author. E-mail: tolga.colak@dpu.edu.tr.

\section{INTRODUCTION}

The investigation of luminescence properties of complexes of rare earth elements was introduced upon the excitation of europium $\beta$-diketone complexes by ultraviolet light in 1942 (1). Biomedical and biolabeling of europium $\beta$-diketone complexes have been a subject of interest since then.
Lanthanides are known for their atomic emission properties. Europium is a versatile lanthanide; a myriad of luminescense applications of europium such as biomedical sensor, diagnosis, drug delivery, and optical screening exist (2-7). One of the most striking properties of the complexes that contain lanthanides is absorption of light with a specific wavelength followed by a reflection with a distinct wavelength. Either a ligand or a metal center are responsible for such absorption behavior. Energy is emitted through various ways, 
which are florescence or phosphorescence, heat, and a photochemical product (8). In the Ln(III)ligand bonding, $4 f$ electrons are screened by the electrons of $5 s^{2}$ and $5 p^{6}$ so that they can rarely take place in covalent interactions with ligands. The covalency of a Ln(III)-ligand bond is around 5$7 \%$. As a result of this screening, transitions are considered weak in respect to both absorption and emission. It is a difficult task to excite $4 \mathrm{f}$ electrons directly unless subjected to a laser, even for highly luminescent materials. Ln(III) ions cannot fluoresce through absorbing UV light $(6,9)$. The lanthanide ion depends on fluorescence ligands in order to transfer to ${ }^{5} D_{j}$ energy level through a viable mechanism, and the absorption of light is similar to an antenna. The long lifetime of the excited states of complex lanthanide ions (0.2-1.5 $\mathrm{ms}$ ), large Stokes slip (over $200 \mathrm{~nm}$ ), and emission at visible region makes them attractive ions in terms of possessing narrow and sharp emission bands (2). Visible emission spectrum of $\mathrm{Eu}^{3+}$ results from ${ }^{5} \mathrm{D}_{0} \rightarrow{ }^{7} \mathrm{~F}_{3}$ transition, and transitions at specific wavelength are: $594 \mathrm{~nm}$ $\left({ }^{5} \mathrm{D}_{0} \rightarrow{ }^{7} \mathrm{~F}_{1}\right) ; 617 \mathrm{~nm}\left({ }^{5} \mathrm{D}_{0} \rightarrow{ }^{7} \mathrm{~F}_{2}\right) ; 659 \mathrm{~nm}\left({ }^{5} \mathrm{D}_{0} \rightarrow{ }^{7} \mathrm{~F}_{3}\right)$, (10).

$\mathrm{Eu}^{3+}$ complexes usually provide higher sensitivity, which accounts for their very strong preference among lanthanides. $\mathrm{Eu}^{3+}$ complexes exhibit some distinct properties such as i) performing absorption pinnacle at UV region (about $330 \mathrm{~nm}$ ) and fluorescence emission at $615 \mathrm{~nm}$, ii) possessing a narrow emission band, iii) considerable lifetime of the triplet state of their complexes under excitation (longer than $100 \mu \mathrm{s}$ ), iv) indicating low background signal, v) demonstrating sharp emission peaks, and $\mathrm{vi}$ ) not causing any radioactive contamination.

$\beta$-diketones or 1,3-diketones consist of two carbonyl groups separated by a carbon atom, which is an a-carbon. On the other hand, carbonyl substituents can be either alkyl, fluorinated alkyl, or aromatic/heteroaromatic groups. The selection of functional groups affect the properties of Eu(III) complexes. For instance, solubility and volatility are increased in organic solvents when branched alkyl chains such as tert-butyl group are introduced. Perfluorinated alkyl groups increase the Lewis acidity. Aromatic $\beta$-diketones better absorb light when compared to aliphatic ones. Furthermore, functional groups affect the energy state of the ligand (singlet and triplet), (11). Fluorescent intensity increases when an electron donor $\left(R_{1}\right)$ and acceptor $\left(R_{2}\right)$ are introduced in the same ligand for $\beta$-diketonato $\left(\mathrm{R}_{1} \mathrm{COCHCOR} \mathrm{COC}_{2}\right)-\mathrm{Eu}$ complexes (12).

The selection of the ligands that will be constituted with europium(III) depends on the application. The ligands used as biolabeling in medical diagnostic kits can be divided into 4 main categories: i) ligands exhibiting no luminescent property, ii) polyamino carboxylate based luminescent ligands (PAC based), iii) $\beta$-Diketone based luminescent ligands, and iv) other luminescent ligands (13).

Luminescent lanthanide $\beta$-diketones have a wide range of applications, including electroluminescent device and sensors, lasers, and bioanalysis (14). Eu(III) complexes are established to be stable in aqueous solutions of $\beta$-diketonates, covalently bonded to the protein easily due to their tendency to chlorosulfonation, and possessing highly luminescent character. Their lesser side products in reactions, ease of their synthesis, and costeffective synthesis can be counted as other advantages (15).

Ultrasensitive bioanalytical kits of analysis are based on the detection of the existence of analyte that bonds to the material of interest or measurement of the concentration (5). The applications regarding the use of luminescent lanthanide complexes in bioanalysis date back to 1983 (16). Most of them are designed for biochemical evaluation or qualitative measurement of specific antibodies or any antigen. Within the possibility of involving radioactive atoms $\left({ }^{125} \mathrm{I},{ }^{3} \mathrm{H}\right.$, and ${ }^{14} \mathrm{C}$ ) that generate signals for some regions, many labels are available. In addition, enzymes, fluorescent probes, chemiluminescent compounds, metals, and metal chelates and liposomes, as nonradioactive labels, can be used due to their numerous advantages (17). This study aims to synthesize the non-radioactive label Eu(III) complex.

Employing ketone and fluorine compounds as precursors, a very limited number of compounds synthesized via Claisen condensation can be found in the literature. Most of them contain aromatic rings. Despite the vast number of synthesis of lanthanide- $\beta$-diketone complexes, very few of them have been utilized in biomolecular labeling (11) by reason of them being only bidentate that makes them have a limited stability. In order to go beyond this limit, tetradentate ligands comprise of two $\beta$-diketones in a molecule were synthesized. These ligands were then used in immunoanalysis for designation of various biomolecules $(18,19)$. This study focuses on the synthesis of tetradentate $\beta$-diketonate based luminescent ligand with eight fluorine atoms and two aromatic rings and its availability on biomolecular labeling.

\section{MATERIALS AND METHODS}

$\mathrm{EuCl}_{3}$, acetophenone, dimethyloctafluoroadipate (DEOFA), sodium methoxide $\left(\mathrm{NaOCH}_{3}\right)$, chlorosulfonic acid $\left(\mathrm{HSO}_{3} \mathrm{Cl}\right)$, diethyl ether, ethanol, and 1,4-dioxane were all provided by SigmaAldrich and used without any purification. NMR 
analysis were carried out by using a Bruker Biospin NMR Spectrometer with data acquisition by taking advantage of an Avance III $400 \mathrm{MHz}$ instrument. FTIR studies were run by a Bruker Vertex 70 FTIR. UV-visible electronic spectra were obtained by a Shimadzu UV-2450 spectrophotometer. Mass spectrometry of the complexes were performed by an Agilent 6530 Accurate Mass Q-TOF LC/MS. Xray single crystallography of $\mathrm{H}_{2} \mathrm{ODIT}$ ligand was studied by using D8-QUEST diffractometer with a graphite-monochromatic Mo-Ka light source at 296 $\mathrm{K}$. The structure was examined by SHELX-2013 $(20,21)$ through direct methods and least squares method was applied to refine the matrix at $\mathrm{F}^{2}$ by taking advantage of WINGX software. Crystalline X-Ray Diffraction data was acquired from Bruker APEX-II (22) diffractometer. Molecular diagrams were generated by MERCURY software (23). Supramolecular analysis was run by WinGX software (24). Luminescence spectrum of the complex was obtained by Perkin Elmer LS55 florescence spectrophotometer.
Synthesis of $\quad(2 Z, 8 Z)-4,4,5,5,6,6,7,7-$ octafluoro-3,8-dihydroxy-1,10-diphenyldeca2,8-diene-1,10-dione ( $\mathrm{H}_{2}$ ODIT)

In order to form the acetophenone sodium salt, $\mathrm{NaOCH}_{3}$ and $50 \mathrm{~mL}$ of diethyl ether in catalytic amount were placed in a two-necked round-bottom flask connected to a refrigeration apparatus. Acetophenone $(2.50 \mathrm{~g}, 20 \mathrm{mmol})$ was slowly added into the flask, and the solution was stirred for $1 \mathrm{~h}$. The observed color was pale light yellow. DEOFA $(3.60 \mathrm{~g}, 10 \mathrm{mmol})$ was added in this solution dropwise. A yellow color was observed. Thin layer chromotography was employed in order to determine the reaction time, amount of matter, and purity in a specific timespan. $n$-Hexanechloroform (1:3, v:v) mixture was used for chromatographic analysis. The solution was stirred for 5 days at room temperature followed by the evaporation of the solvent. The residue was dissolved with water. $\mathrm{pH}$ adjustment $(\mathrm{pH}=6)$ was later carried out with $15 \% \quad \mathrm{H}_{2} \mathrm{SO}_{4}$. Precipitated substance at acidic medium was dried and crystallized from ethanol-1,4-dioxane (3:2, v:v) mixture (Scheme 1). Yield: $2.50 \mathrm{~g}$ (48.5 \%).<smiles>CC#CC#CC#CC(=O)c1ccccc1C[NH2+]C#CC(=O)c1ccccc1</smiles>

Scheme 1: Reagents and conditions. (i) $\mathrm{NaOCH}_{3}$, diethyl ether, rt, $1 \mathrm{~h}$; (ii) DEOFA, rt, 5 days; (iii) $\mathrm{H}_{2} \mathrm{SO}_{4}, \mathrm{H}_{2} \mathrm{O}$.

Synthesis of $(2 Z, 8 Z)-1,10-b i s(b e n z e n e-1-$ sulfonyl chloride)-4,4,5,5,6,6,7,7-octafluoro3,8-dihydroxydeca-2,8-diene-1,10-dione ( $\mathrm{H}_{2}$ CODIT)

$\mathrm{H}_{2}$ ODIT $(0.98 \mathrm{~g}, 2 \mathrm{mmol}$ ) compound was added slowly in $\mathrm{HSO}_{3} \mathrm{Cl}(5 \mathrm{~mL})$ that was placed in a balloon under refrigeration apparatus. The color of the solution turned to light green from yellow followed by a dark green color when the whole material was introduced into the solution. The solution was stirred for 5 days at room temperature. To abandon the excess chlorosulfonic acid, solution was dripped onto ice-water. A yellow solid was formed in ice-water. The solution was then filtered, rinsed with cold water, and dried (Scheme 2). Yield: 0,99 g (72\%). 
<smiles>O=C(/C=C(\O)C(F)(F)C(F)(F)F)C(F)(F)C(F)(F)F</smiles><smiles>O=C(/C=C(\O)C(F)(F)C(F)(F)C(F)(F)F)C(O)=CC(=O)c1ccccc1S(=O)(=O)OCl</smiles>

Scheme 2: Synthesis of $\mathrm{H}_{2}$ CODIT compound.

$$
\mathrm{H}_{2} \text { CODIT }
$$

\section{Synthesis of the Eu(III) complex}

Chlorosulfonated ligand ( $\mathrm{H}_{2}$ CODIT) $(0.97 \mathrm{~g}, 1.4$ $\mathrm{mmol})$ was dissolved in ethanol. $\mathrm{EuCl}_{3}(0.18 \mathrm{~g}$, $0.70 \mathrm{mmol}$ ) was introduced in the stirring solution resulting that complexation occurs very rapidly.
Subsequent to abandoning of ethanol, the obtained solid material was rinsed with water and diethyl ether followed by drying (Scheme 3). Yield: $0.87 \mathrm{~g}$ $(81 \%)$.

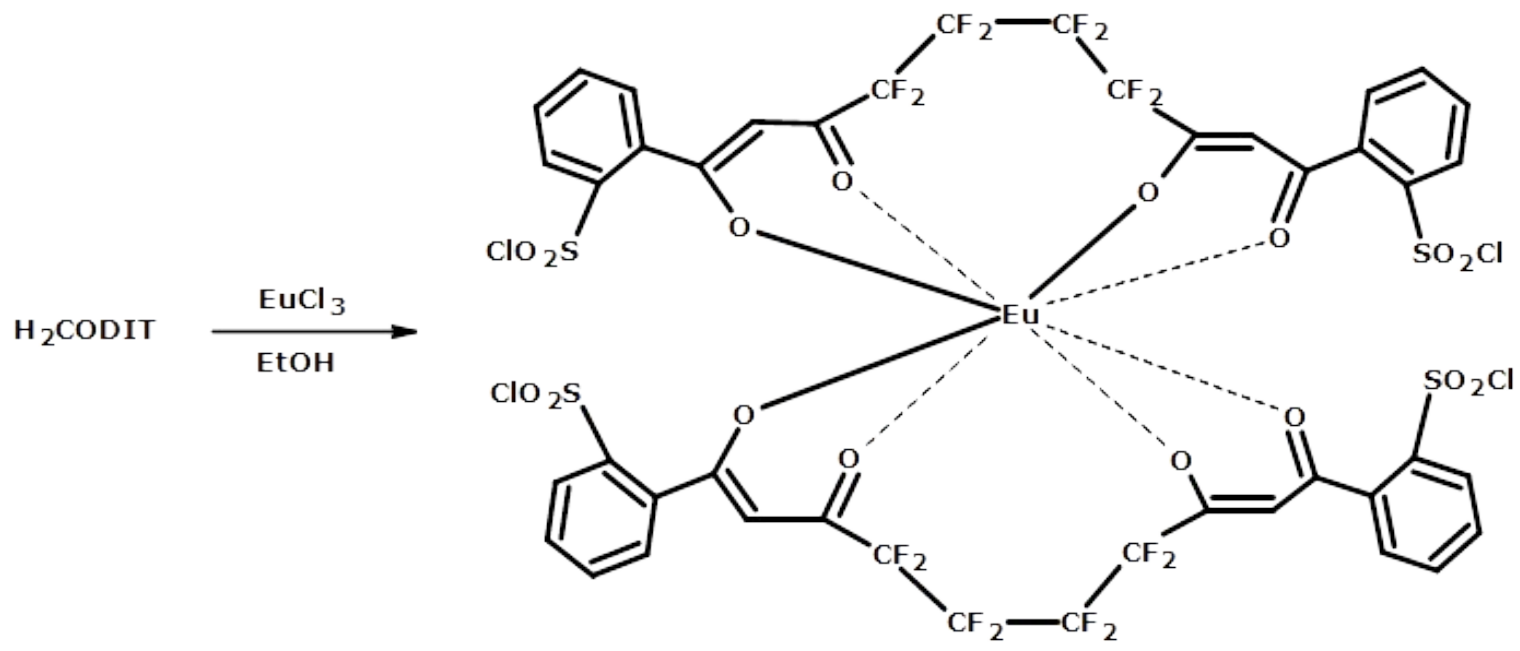

Scheme 3. Synthesis of Eu(III) complex.

\section{RESULTS AND DISCUSSION}

\section{Spectroscopic studies}

While the the structure of the the synthesized $\mathrm{H}_{2} \mathrm{ODIT}$ compound was illuminated via ${ }^{1} \mathrm{H}-\mathrm{NMR}$ and ${ }^{13} \mathrm{C}-\mathrm{NMR}$ spectroscopy, mass spectrometry, X-ray single crystal diffactometry and FT-IR techniques, ${ }^{1} \mathrm{H}-\mathrm{NMR}$ and ${ }^{13} \mathrm{C}-\mathrm{NMR}$ spectroscopy, mass spectrometry, and FT-IR were employed for the characterization of the $\mathrm{H}_{2}$ CODIT ligand. Structural properties of the complex was determined by FTIR, mass, luminescence spectroscopy, and UVVisible techniques.

\section{FTIR spectra}

ATR technique was employed in obtaining the FTIR spectra of the ligands and complexes in the range of $4000-550 \mathrm{~cm}^{-1}$ and characteristic vibrations were determined.

FTIR spectrum of DEOFA is given in Figure $1 \mathrm{a}$. The absorption band at $1778 \mathrm{~cm}^{-1}$ results from $\mathrm{C}=\mathrm{O}$ stretching (-CO-OR). Two other absorption bands at 1181 and $1142 \mathrm{~cm}^{-1}$ were observed and these bands were assigned to $-\mathrm{CF}_{2}$ group vibrations. The stretching vibration absorption band at $2994 \mathrm{~cm}^{-1}$ could be assigned to the aliphatic $\mathrm{C}-\mathrm{H}$ group.

In the FTIR spectrum of $\mathrm{H}_{2} \mathrm{ODIT}$ compound (Figure $1 b)$, the peaks observed at 1595 and $1565 \mathrm{~cm}^{-1}$ belong to tautomeric state keto and enol form carbonyls $\mathrm{v}(\mathrm{C}=\mathrm{O})$, respectively. $\mathrm{v}(\mathrm{C}=\mathrm{C})$ and $\mathrm{v}(\mathrm{C}-\mathrm{O})$ vibration bands of enol form correspond to 1466 and $1228 \mathrm{~cm}^{-1}$, respectively. Two sharp peaks at 
1185 and $1156 \mathrm{~cm}^{-1}$ belong to $\mathrm{v}\left(\mathrm{CF}_{2}\right)$ vibrations. The intense peak observed at $751 \mathrm{~cm}^{-1}$ results from the vibration that belongs to the monosubstituted benzene ring (25).

$\mathrm{v}\left(\mathrm{SO}_{2} \mathrm{Cl}\right)$ vibration peak is observed in FTIR spectrum of the $\mathrm{H}_{2}$ CODIT compound (Figure 1c) apart from $\mathrm{H}_{2} \mathrm{ODIT}$ compound. Asymmetric vibration of sulfonyl chloride group gives a peak at $1343 \mathrm{~cm}^{-1}$. On the other hand, two peaks at 842 and $806 \mathrm{~cm}^{-1}$ exhibit the disubstituted bonding to benzene ring (25).

FTIR spectrum of Eu(III) complex is given in Figure $1 d$. The peak observed at $1604 \mathrm{~cm}^{-1}$ relates to the $\mathrm{v}(\mathrm{C}=\mathrm{O})$ vibration of keto form carbonyl that does not bond to the metal in $\mathrm{H}_{2}$ CODIT compound. On the other hand, peaks observed at $1564 \mathrm{~cm}^{-1}$ and $1404 \mathrm{~cm}^{-1}$ belong to $\mathrm{v}(\mathrm{C}=\mathrm{O})$ and $\mathrm{v}(\mathrm{C}=\mathrm{C})$ vibrations of enolic structure, respectively. Characteristic vibration bands shift to lower frequencies in $\beta$ diketone complex for the free ligand. This shift arises from the acidic proton loss of enolic structure from hydroxyl group and bonding of enolic hydroxyl oxygen and enolic carbonyl oxygen to the metal ion in the chelate mode (26). The peak that is coherent to the $\mathrm{v}\left(\mathrm{CF}_{2}\right)$ vibrations in the ligand is at $1240 \mathrm{~cm}^{-1}$ and $\mathrm{v}\left(\mathrm{SO}_{2} \mathrm{Cl}\right)$ vibrations result in the peak at $1171 \mathrm{~cm}^{-1}(25)$. The emergent absorption band observed at $510 \mathrm{~cm}^{-1}$ in the complex suggests the existence of Eu-O coordination bond $(27,28)$.

\section{Mass Spectra}

Mass spectrometric results obtained from $\mathrm{H}_{2} \mathrm{ODIT}$ molecule in chloroform solution are presented in Figure 2. Investigating the mass spectrometry of $\mathrm{H}_{2}$ ODIT ligand, addition of one hydrogen to this ligand results in a strong molecular ion peak at $\mathrm{m} / \mathrm{z} 495.08$ that corresponds to the $\left[\mathrm{H}_{2} \mathrm{ODIT}+\mathrm{H}\right]^{+}$ ion. The peak observed at $\mathrm{m} / \mathrm{z} 517.07$ corresponds to the $\left[\mathrm{H}_{2} \mathrm{ODIT}+\mathrm{Na}\right]^{+}$ion whereas the peak at $\mathrm{m} / \mathrm{z}$ 518.07 belongs to the $\left[\mathrm{H}_{2} \mathrm{ODIT}+\mathrm{Na}+\mathrm{H}\right]$ ion.
$\mathrm{H}_{2}$ ODIT structure is supported by the mass spectrometric data.

The mass spectra of ligand $\mathrm{H}_{2}$ CODIT was recorded in chloroform solution is presented in Figure $3 a$. The mass spectra of $\mathrm{H}_{2} \mathrm{CODIT}$ showed accurate molecular ion peak at $\mathrm{m} / \mathrm{z}$ 691.03, matched with the theoretical value. Two molecular ion peaks at 690.34 and 693.99 in the spectrum correspond to one hydrogen atom subtraction and two hydrogen atoms addition in the molecular ion peak, respectively.

Mass spectrum that belongs to Eu(III) complex in ethanol as solvent is given in Figure $3 \mathrm{~b}$. The product ion at $\mathrm{m} / \mathrm{z} 1532.78$ in the spectrum was observed through the introduction of protonated ion were resulted from the molecular ion peak of the ligand. The structure shown in the spectrum, which has the most bonding abundance, has a peak at $\mathrm{m} / \mathrm{z}$ 1018.23.

\section{NMR Spectroscopy}

${ }^{1} \mathrm{H}-\mathrm{NMR}$ and ${ }^{13} \mathrm{C}-\mathrm{NMR}$ spectra of the ligands were recorded in benzene- $\mathrm{d}_{6}$ as solvent. ${ }^{1} \mathrm{H}$ NMR and ${ }^{13} \mathrm{C}-$ NMR of $\mathrm{H}_{2} \mathrm{ODIT}$ are presented in Figures 4 and 5, respectively. Due to the symmetry of the compounds in the solution, half of the molecules were taken into consideration when the spectra were being acquired.

For ${ }^{1} \mathrm{H}$ NMR spectrum of the $\mathrm{H}_{2} \mathrm{ODIT}$ ligand, the triplet that belongs to the $\mathrm{H}_{\mathrm{a}}$ proton bonded to aromatic ring was observed in the range of 6.92 $6.89 \mathrm{ppm}$ whereas the triplet that belongs to $\mathrm{H}_{\mathrm{b}}$ protons in the range of 7.07-7.03 ppm. The doublet belonging to $\mathrm{H}_{\mathrm{c}}$ protons were observed in the range of $7.45-7.43 \mathrm{ppm}$. The singlet at 6.42 ppm that belong to the active alpha proton $(-\mathrm{CH})$ neighboring the carbonyl group suggests the formation of the $(-\mathrm{HC}=\mathrm{C})$ functional group, as a result of keto-enol tautomeric equilibrium in the structure, and a possible intramolecular hydrogen bond $(\mathrm{O}-\mathrm{H} \cdots \mathrm{O})$, (Figure $4 \mathrm{a})$. 

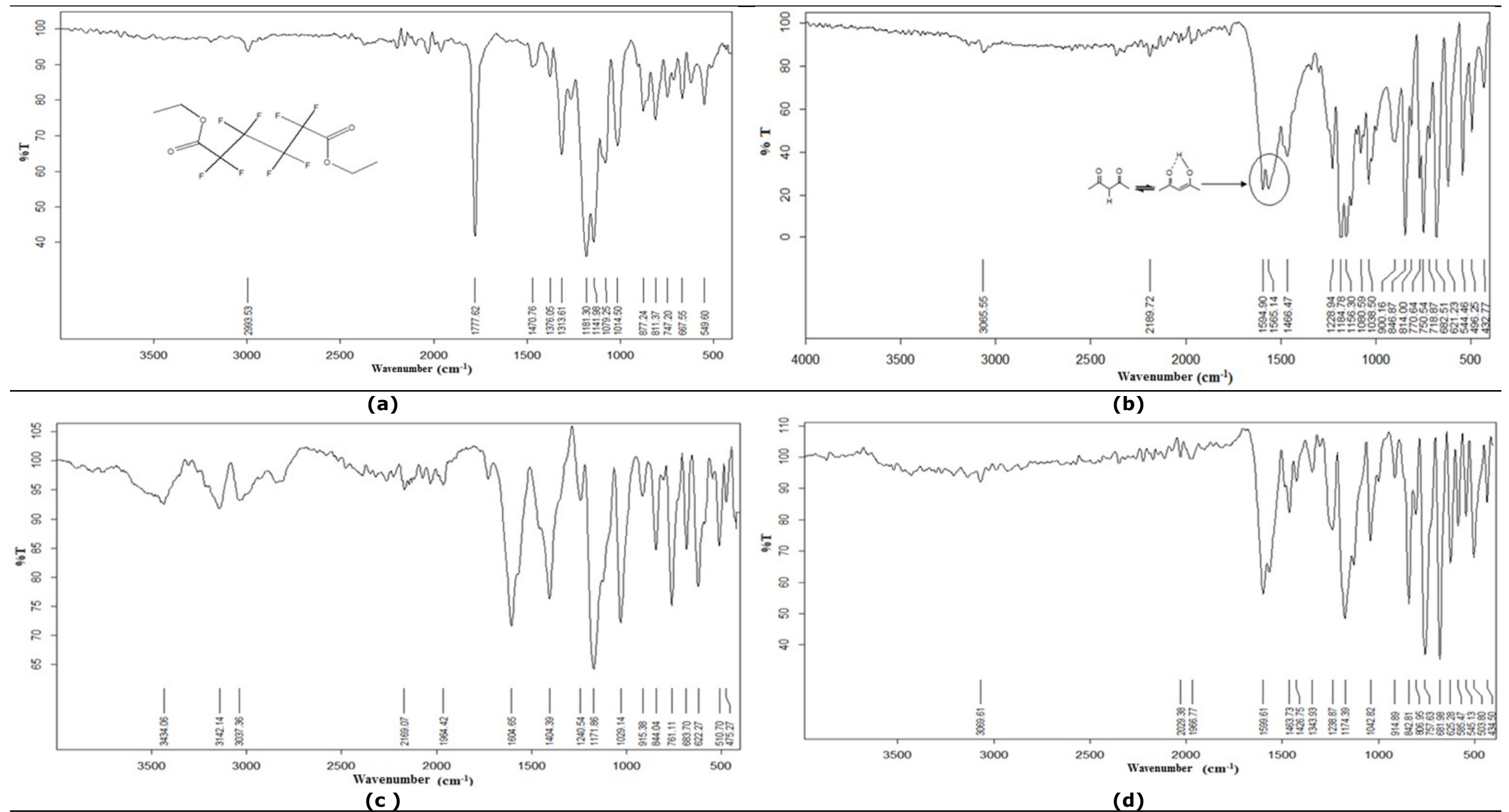

Figure 1: FTIR spectra of (a) DEOFA, (b) $\mathrm{H}_{2} \mathrm{ODIT}$, (c) $\mathrm{H}_{2}$ CODIT, and (d) $\mathrm{Eu}(\mathrm{III})$ compounds. 


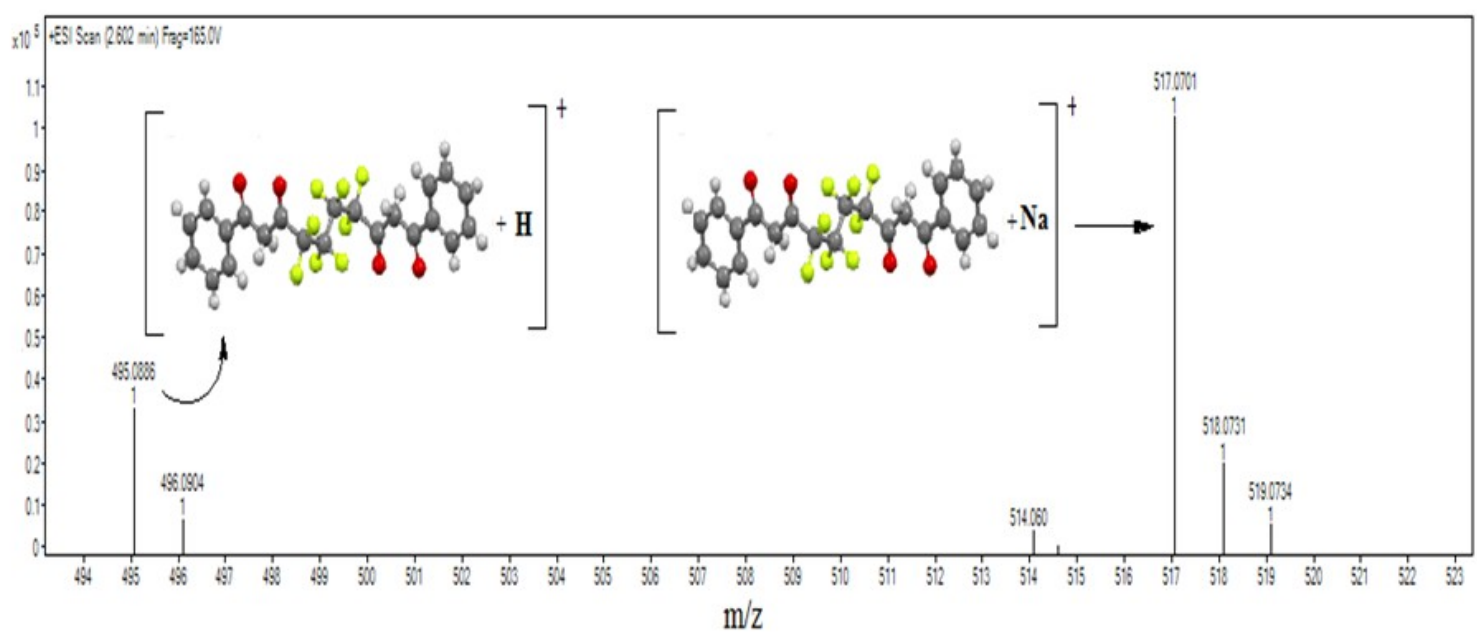

Figure 2: Mass spectrum of $\mathrm{H}_{2} \mathrm{ODIT}$ ligand.

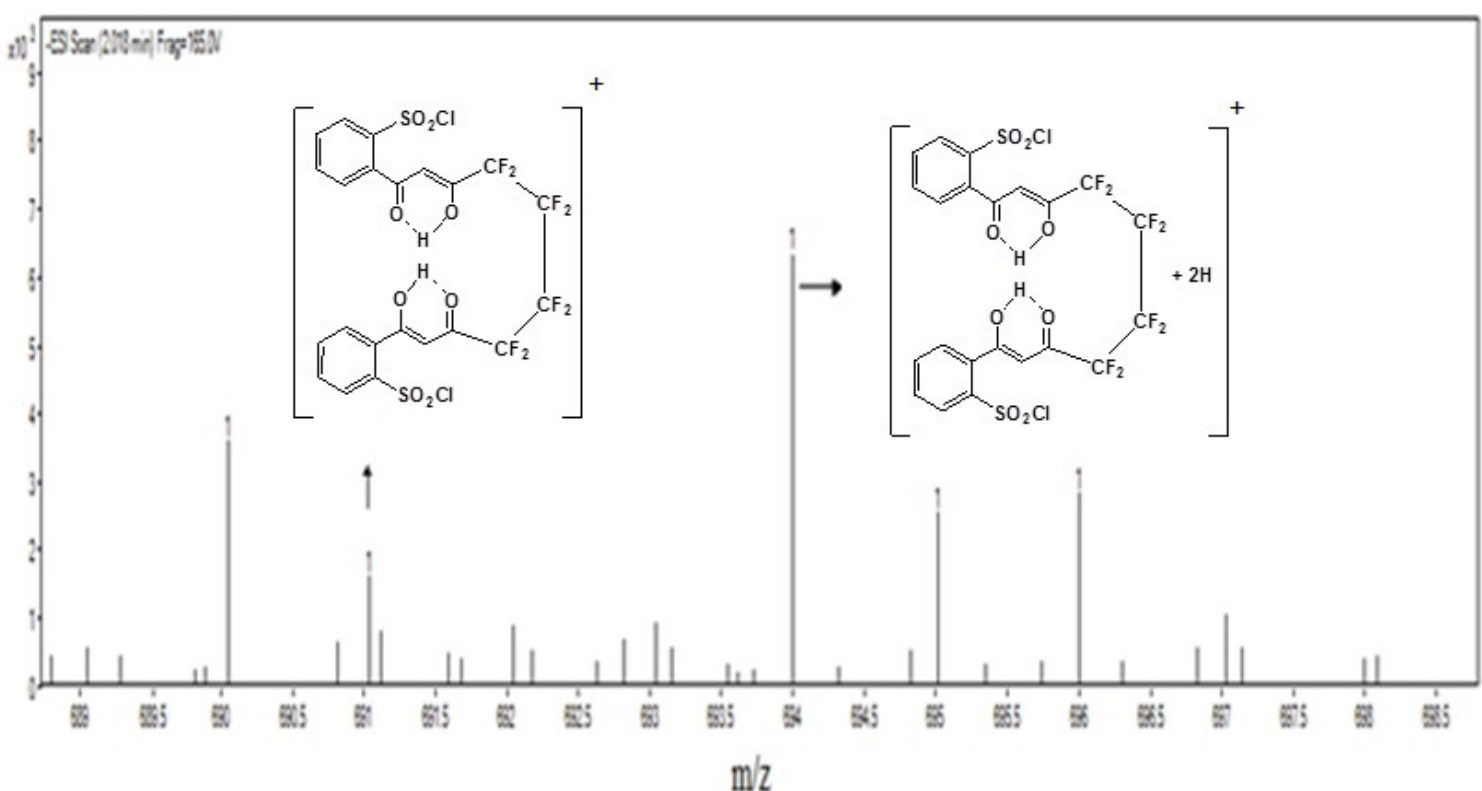

(a) 


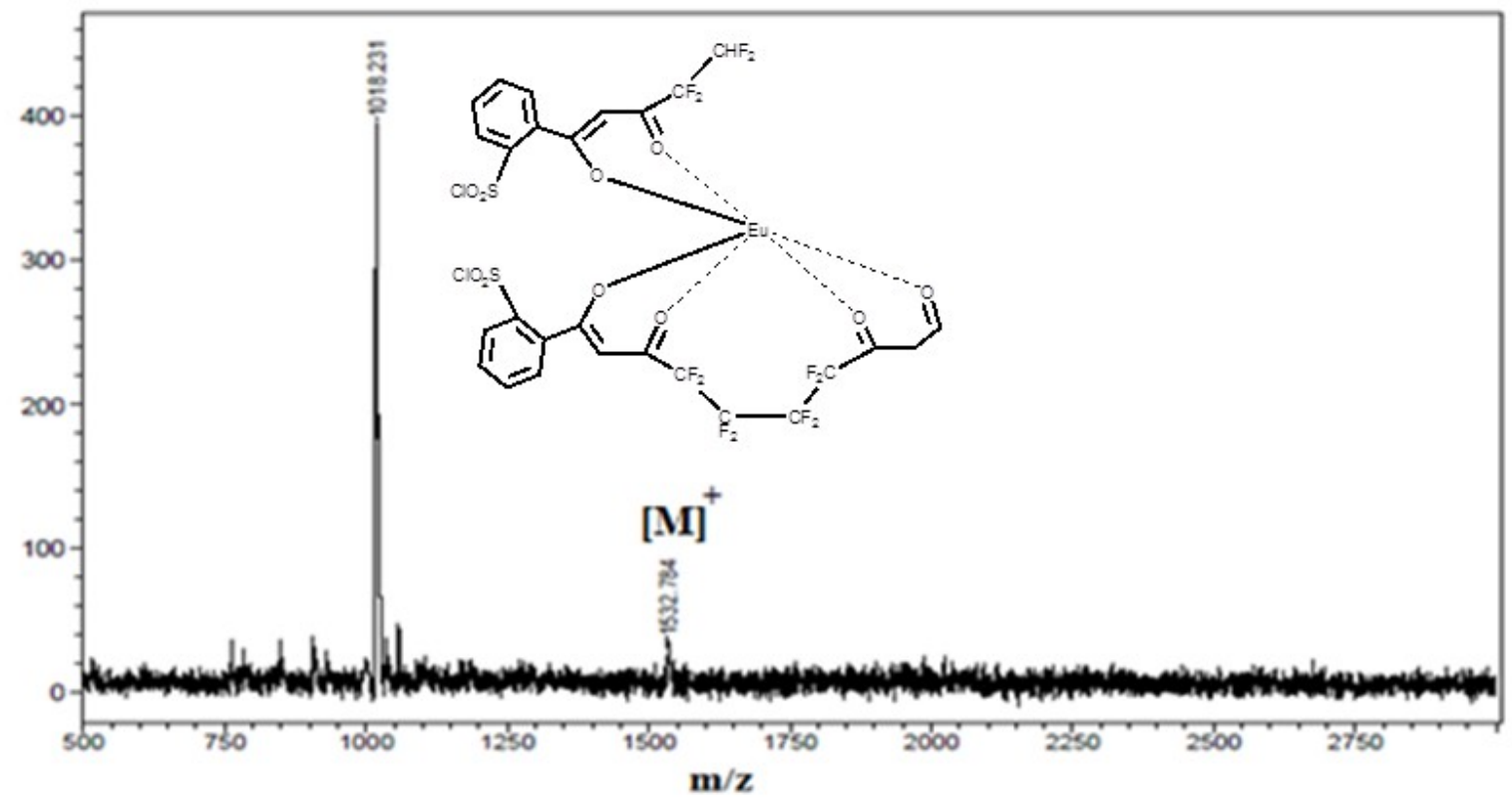

(b)

Figure 3: Mass spectra of the compounds: (a) $\mathrm{H}_{2} \mathrm{CODIT}$, (b) $\mathrm{Eu}(\mathrm{III})$ chelate.

When the ${ }^{1} \mathrm{H}$ NMR spectrum of $\mathrm{H}_{2}$ CODIT ligand was investigated, $\mathrm{H}_{a}$ and $\mathrm{H}_{\mathrm{b}}$ protons bonded to aromatic ring were observed in the range of 7.45-7.44 and 7.42-7.41 ppm as two doublets, respectively. On the other hand, $\mathrm{H}_{\mathrm{c}}$ proton was detected in the range of 7.02-7.06 ppm as triplet, and $\mathrm{H}_{\mathrm{d}}$ protons were detected in the range of 6.92-6.90 ppm also as triplet. Active alpha proton belonging to the $\mathrm{H}_{2}$ CODIT ligand was established at $6.41 \mathrm{ppm}$ as singlet (Figure 4b).

When the ${ }^{13} \mathrm{C}-\mathrm{NMR}$ spectrum of the $\mathrm{H}_{2} \mathrm{ODIT}$ ligand was observed, the peaks that belong to aromatic ring carbons are surveyed in the range of 127.21-132.94 ppm. The carbon, which belongs to $(-\mathrm{HC}=)$ group, exhibiting keto-enol tautomer balance in the structure resonated at $93.27 \mathrm{ppm}$. Keto and enol carbons are characterized at 184.94 and 179.09 ppm, respectively. The peaks at 109.95 and 126.97 ppm belong to the carbon of $\left(-\mathrm{CF}_{2}\right)$ group (Figure 5a).

The carbons bonded to the aromatic ring in the ${ }^{13} \mathrm{C}-\mathrm{NMR}$ spectrum of $\mathrm{H}_{2} \mathrm{CODIT}$ ligand resonated in the range of 126.97-132.95 ppm. Keto-enol tautomeric equilibrium exhibits a peak at 93.28 ppm, belonging to the $(-\mathrm{HC}=)$ group. Keto tautomer carbonyl carbon and enol carbon resonated at $184.94 \mathrm{ppm}$ and $178.83 \mathrm{ppm}$, respectively (Figure $5 \mathrm{~b}$ ). 


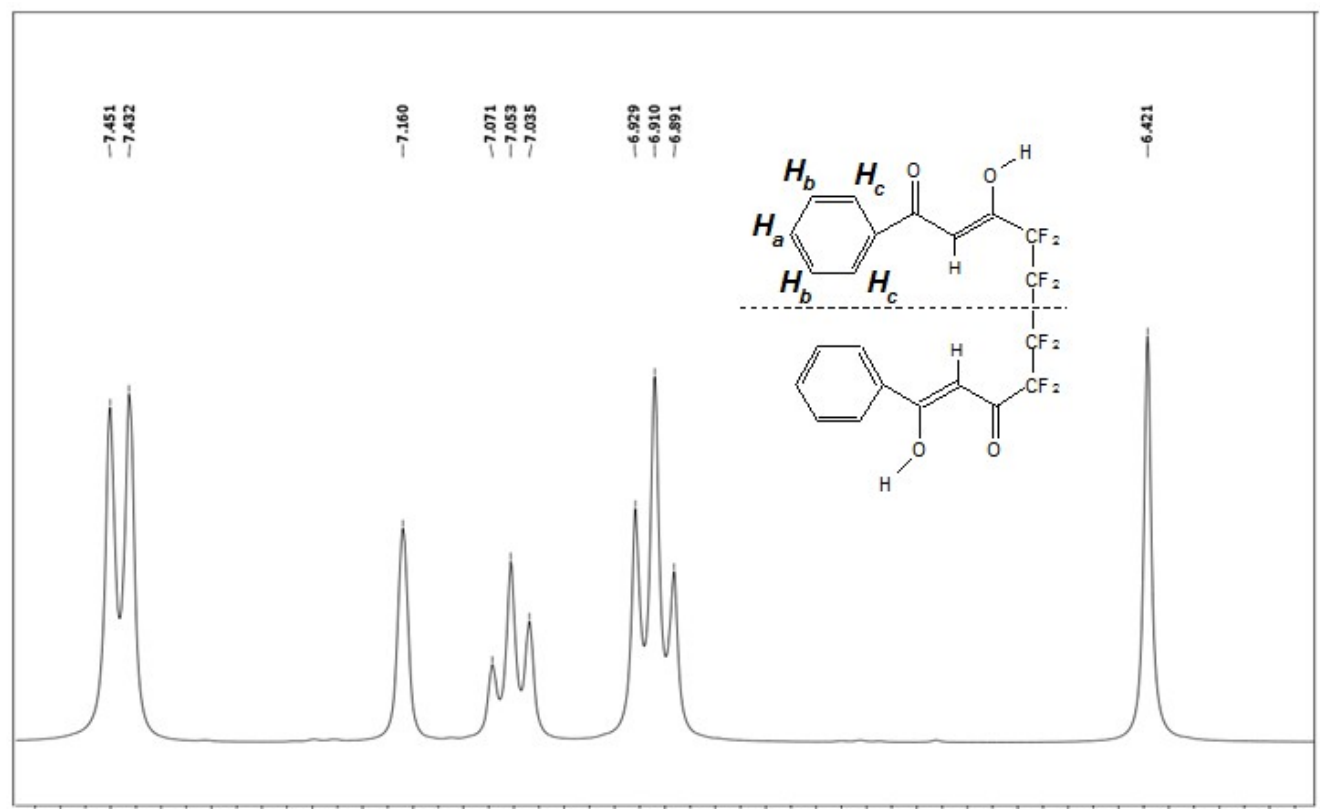

$\begin{array}{lllllllllllllllllllllllllllllllll}7.50 & 7.45 & 7.40 & 7.35 & 7.30 & 7.25 & 7.20 & 7.15 & 7.10 & 7.05 & 7.00 & 6.95 & 6.90 & 6.85 & 6.80 & 6.75 & 6.70 & 6.65 & 6.60 & 6.55 & 6.50 & 6.45 & 6.40 & 6.35 & 6.30\end{array}$

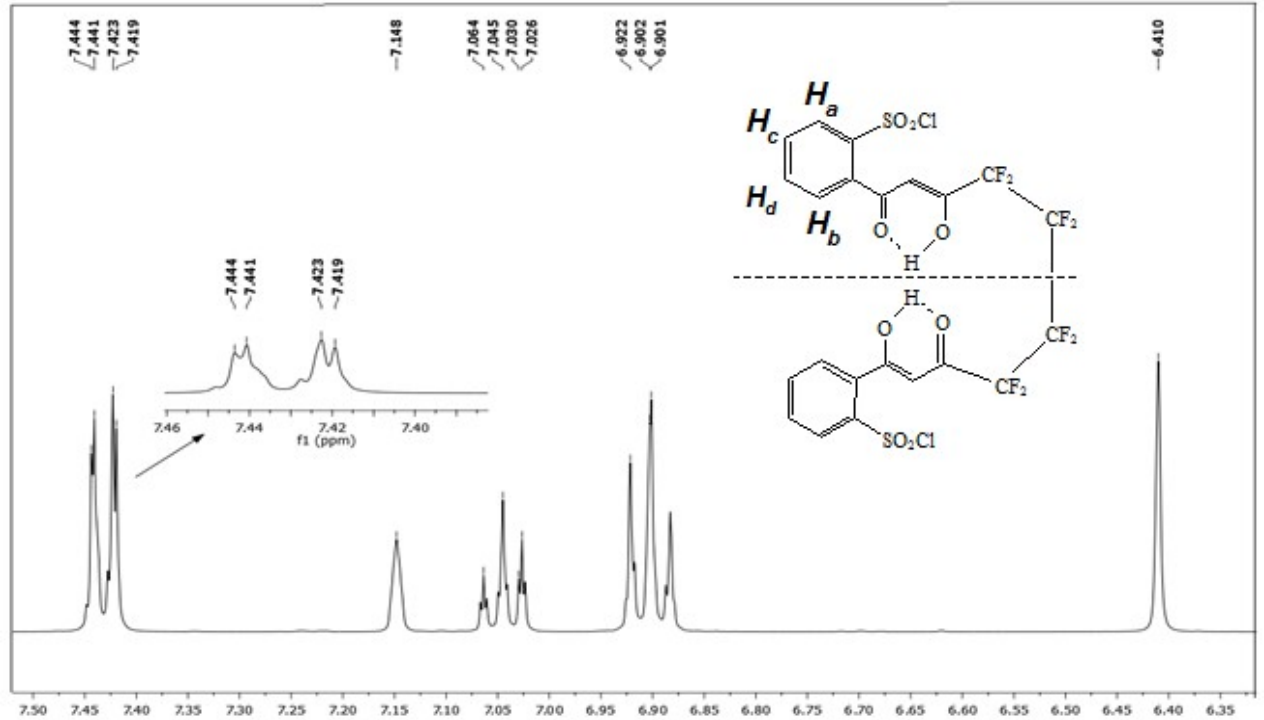

Figure 4: ${ }^{1} \mathrm{H}$ NMR spectra of the ligands: (top) $\mathrm{H}_{2}$ ODIT, (bottom) $\mathrm{H}_{2}$ CODIT. 


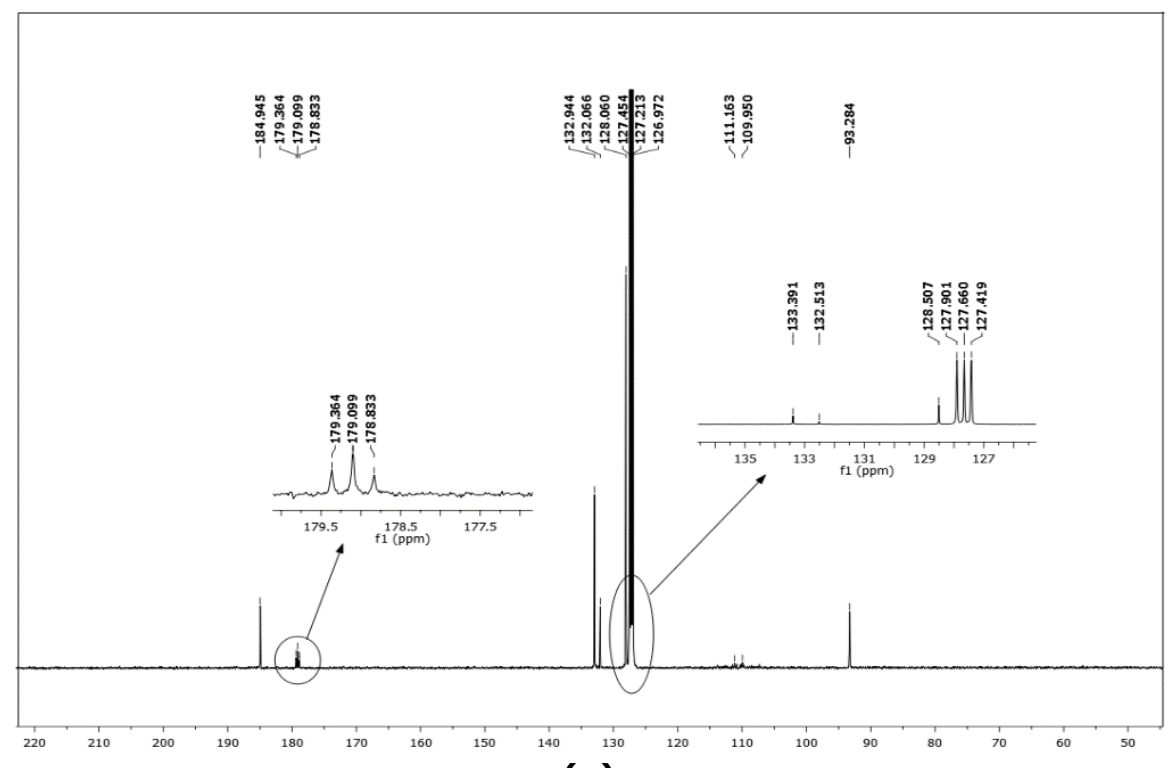

(a)

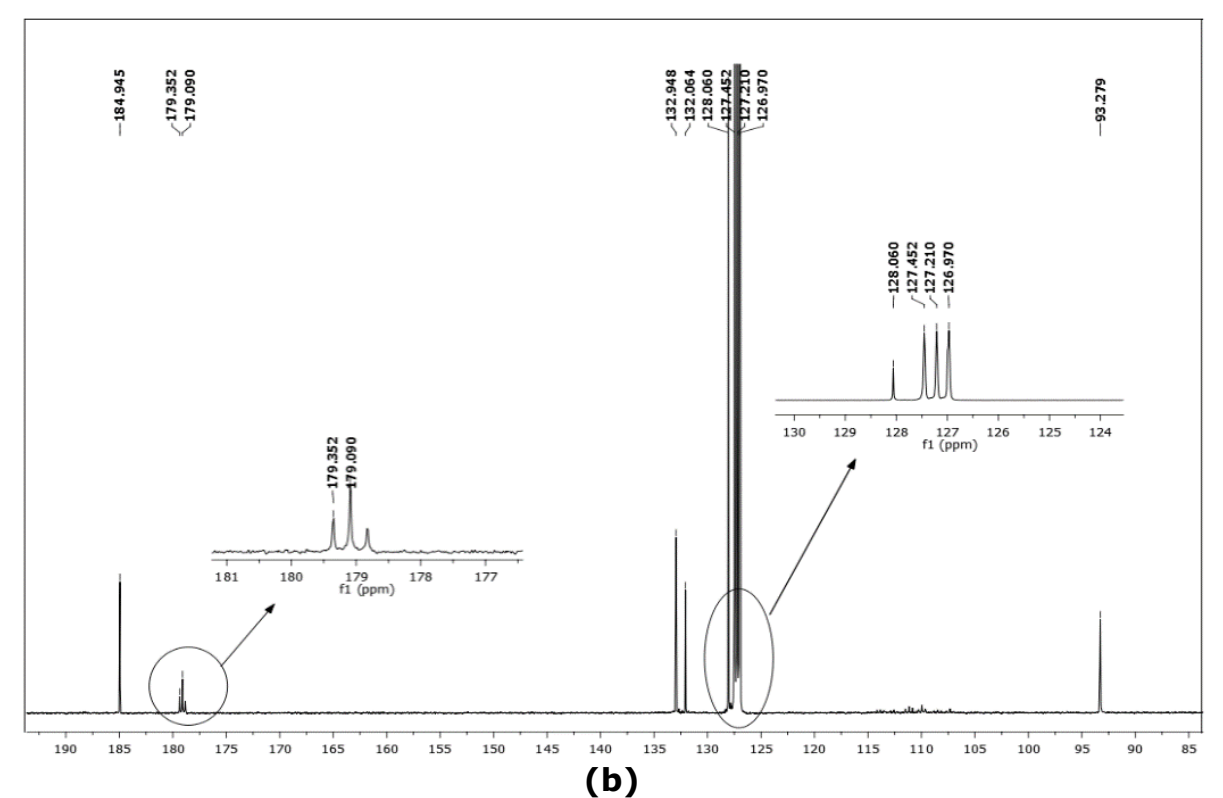

(b)

Figure 5: ${ }^{13} \mathrm{C}$ NMR spectra of the ligands: (a) $\mathrm{H}_{2} \mathrm{ODIT}$, (b) $\mathrm{H}_{2}$ CODIT. 


\section{UV-Visible Spectra}

UV-visible absorption spectrum of $\mathrm{H}_{2} \mathrm{ODIT}$ compound was observed in a $10^{-4} \mathrm{M}$ ethanolic solution (Figure 6a). The band at $265 \mathrm{~nm}$ visible light short wavelength belongs to aromatic ring $\Pi \rightarrow \Pi^{*}$ transition. The second band observed at
$318 \mathrm{~nm}$ wavelength belongs to $\mathrm{n} \rightarrow \Pi^{*}$ electronic transition of keto and enol carbonyl group of the tautomer. Lastly, the band observed at $329 \mathrm{~nm}$ ( $\varepsilon=38660 \mathrm{~L} \mathrm{~mol}^{-1} \mathrm{~cm}^{-1}$ ) corresponds to $\Pi \rightarrow \Pi^{*}$ transition of conjugation and delocalization of the ligand in the electronic system $(29,30)$.

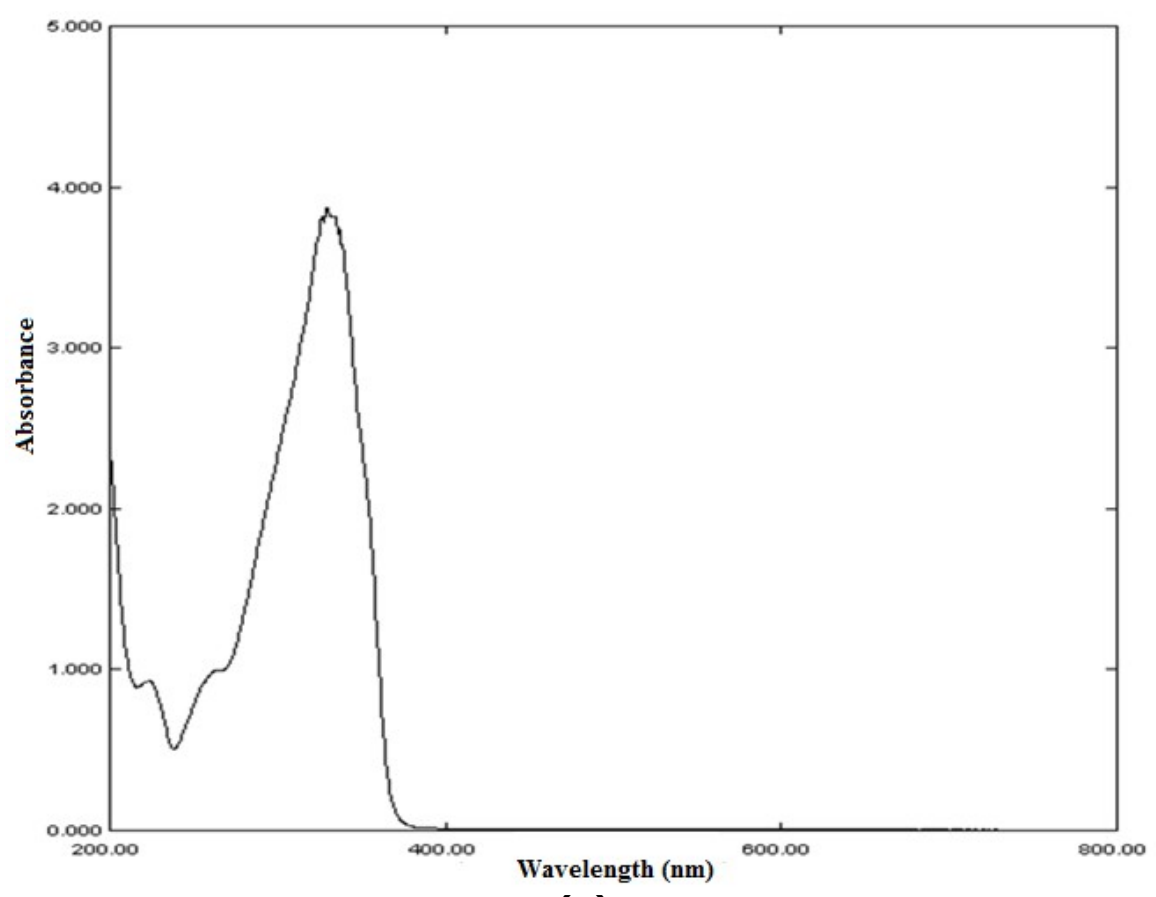

(a)

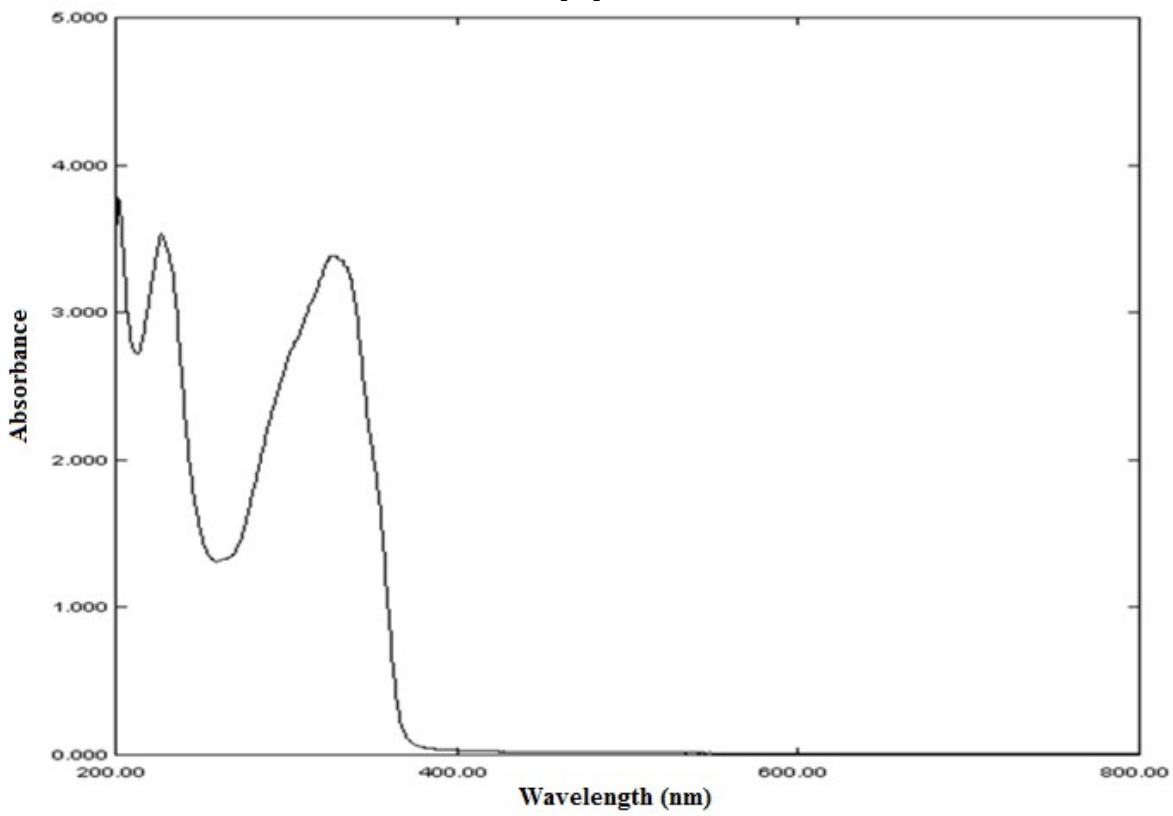

(b)

Figure 6: UV-visible spectra of (EtOH, $\left.1.0 \times 10^{-4} \mathrm{M}\right)$, (a) $\mathrm{H}_{2} \mathrm{ODIT}$, (b) $\mathrm{H}_{2} \mathrm{CODIT}$ ligands.

$\mathrm{H}_{2} \mathrm{CODIT}$ compound was characterized in $10^{-4} \mathrm{M}$ ethanolic solution (Figure $6 \mathrm{~b}$ ). Three absorption bands at 268,318 and $325 \mathrm{~nm}(\varepsilon=33850$
$\mathrm{Lmol}^{-1} \mathrm{Cm}^{-1}$ ) resulting from $\mathrm{n \rightarrow \Pi ^{* }}$ and $\mathrm{n} \rightarrow \Pi^{*}$ electronic transition were observed at UV-visible absorption spectrum. 
UV-Visible spectrum of the complex in $10^{-4} \mathrm{M}$ aqueous solution has an $\varepsilon$ value of $91600 \mathrm{~L}$ mol $1 \mathrm{~cm}^{-1}$ at $268 \mathrm{~nm}$, which belongs to $\Pi \rightarrow \Pi^{*}$ and $\mathrm{n} \rightarrow \Pi^{*}$ transitions whereas the band at $321.5 \mathrm{~nm}$ possessing a considerably high value of $\varepsilon=$ $28980 \mathrm{~L} \mathrm{~mol}^{-1} \mathrm{~cm}^{-1}$ belongs to the charge transfer to the metal from the ligand (Figure 7).

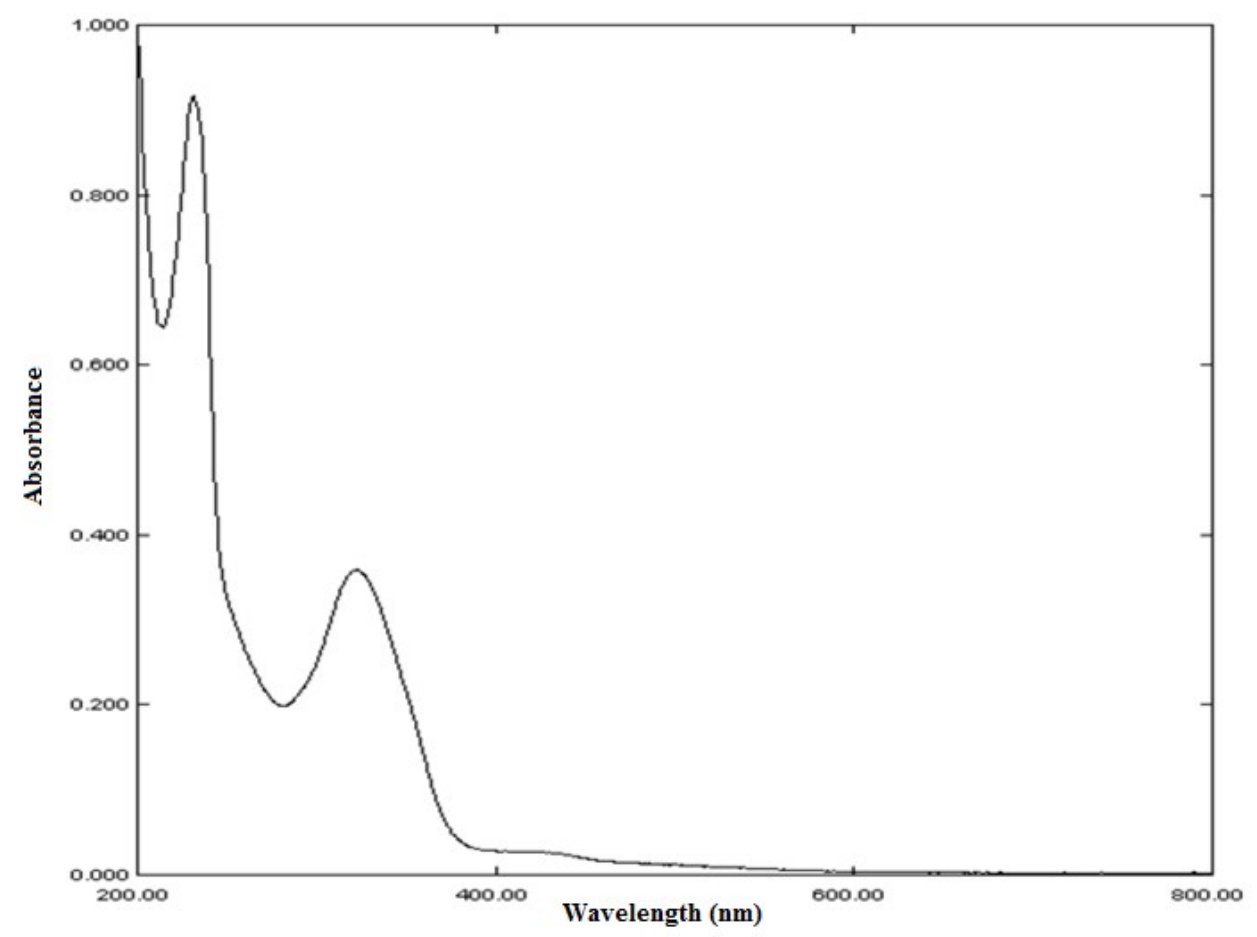

Figure 7: UV-Visible spectrum of the complex $\left(\mathrm{H}_{2} \mathrm{O}, 1.0 \times 10^{-5} \mathrm{M}\right)$.

\section{X-Ray Diffraction Analysis}

Crystallographic data and refinement details of $\mathrm{H}_{2} \mathrm{ODIT}$ are presented in Table 1 ; selected bond distances, angles and hydrogen bond geometries are listed in Table 2. $\mathrm{H}_{2} \mathrm{ODIT}$ ligand belongs to the $P 2_{1} / C$ space group. As seen in Figure 8 , a center of symmetry located on the mid position $(1 / 2,1 / 2,0)$ of $\mathrm{C}-\mathrm{C}$ [C11-C $\left.11^{i}\right]$ bond exists. The $\mathrm{C} 9-\mathrm{O} 2$ bond is typical double bond [1.245 (2) $\AA$ ], while the C7-O1 bond is single bond [1.314 (2) $\AA$ ]. The molecules of $\mathrm{H}_{2} \mathrm{ODIT}$ are connected by $\Pi \cdots n$ interactions. The $\Pi \cdots \Pi$ contact between the phenyl rings may stabilize the structure, with centroid-centroid distance of 3.992(3) ̊. As seen in Figure 9, $\Pi \cdots \Pi$ interactions maintain the packing along [111] direction. 


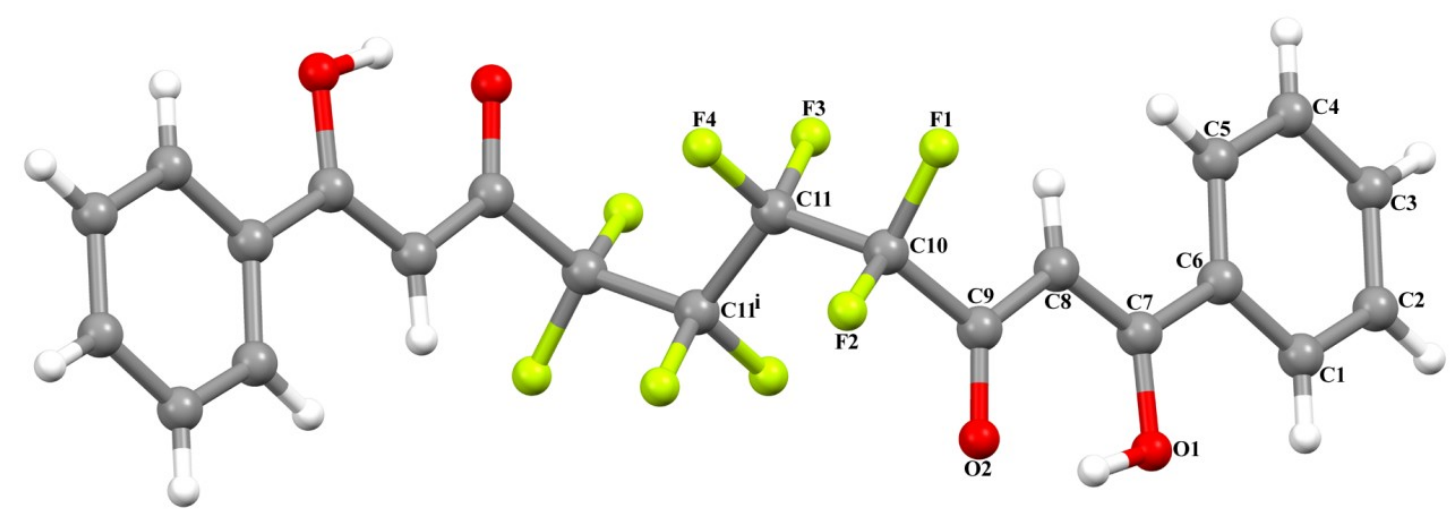

Figure 8: The molecular structure of $\mathrm{H}_{2} \mathrm{ODIT}$ showing the atom numbering scheme. $[(\mathrm{i})-\mathrm{x}+1,-$ $y+1,-z]$.

Table 1. Crystal data and structure refinement parameters for $\mathrm{H}_{2} \mathrm{ODIT}$. Empirical formula $\mathrm{C}_{22} \mathrm{H}_{14} \mathrm{~F}_{8} \mathrm{O}_{4}$

Formula weight Crystal system Space group $a(\AA)$

$b(\AA)$

$c(\AA)$

$\beta\left({ }^{\circ}\right)$ $V\left(\AA^{3}\right)$

Z

$D_{\mathrm{c}}\left(\mathrm{g} \mathrm{cm}^{-3}\right)$

$\mu\left(\mathrm{mm}^{-1}\right)$

$\theta$ range $(0)$

Measured refls.

Independent refls.

$R_{\text {int }}$

$\mathrm{S}$

$\mathrm{R} 1 / \mathrm{wR} 2$

$\Delta \mathbf{X}_{\max } / \Delta \mathbf{X}_{\min }\left(\mathrm{e} \AA^{-3}\right)$
494.33

Monoclinic

$\mathrm{P} 2{ }_{1} / \mathrm{C}$

$8.168(5)$

11.385 (5)

11.425 (5)

104.042 (5)

1030.7 (9)

2

1.593

0.16

3.1-28.3

20454

2552

0.027

1.06

$0.043 / 0.114$

$0.28 /-0.18$

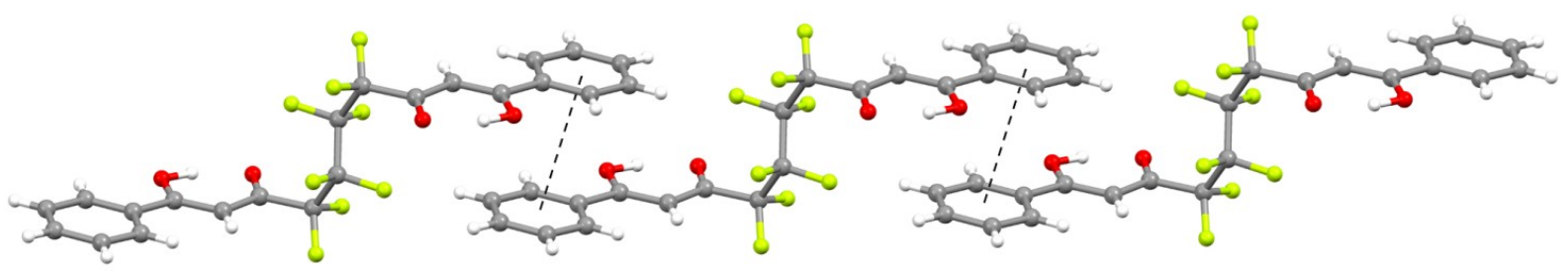

Figure 9. The $\Pi \cdots \Pi$ interactions in $\mathrm{H}_{2} \mathrm{ODIT}$. 
Table 2: Selected bond distances and angles, hydrogen bond parameters for $\mathrm{H}_{2} \mathrm{ODIT}\left(\AA^{\circ}{ }^{\circ}\right)$.

\begin{tabular}{|c|c|c|c|c|}
\hline \multicolumn{5}{|c|}{ Bond distances $(\AA)$} \\
\hline $\mathrm{C} 10-\mathrm{F} 1$ & $1,3596(19)$ & & C10-F2 & $1.3478(18)$ \\
\hline C11-F3 & $1,3475(18)$ & & $\mathrm{C} 11-\mathrm{F} 4$ & $1,3519(18)$ \\
\hline $\mathrm{C} 9-\mathrm{O} 2$ & $1,245(2)$ & & C7-O1 & $1,314(2)$ \\
\hline \multicolumn{5}{|c|}{ Bond angles ( $\left.{ }^{\circ}\right)$} \\
\hline $\mathrm{C} 7-\mathrm{O} 1-\mathrm{H} 1 \mathrm{~A}$ & $105.0(19)$ & & $\mathrm{O2-C9-C8}$ & $125.77(15)$ \\
\hline $\mathrm{O} 1-\mathrm{C} 7-\mathrm{C} 8$ & $120.67(15)$ & & $\mathrm{O} 1-\mathrm{C7}-\mathrm{C} 6$ & $115.02(14)$ \\
\hline $\mathrm{F} 2-\mathrm{C} 10-\mathrm{F} 1$ & $107.33(13)$ & & $=3-\mathrm{C} 11-\mathrm{F} 4$ & $107.70(13)$ \\
\hline \multicolumn{5}{|c|}{ Hydrogen bond parameters $\left(\AA,{ }^{\circ}\right)$} \\
\hline$D-H \cdots A$ & $\mathrm{D}-\mathrm{H}$ & $H \cdots A$ & $D \cdots A$ & $\mathrm{D}-\mathrm{H} \cdots \mathrm{A}$ \\
\hline $\mathrm{O} 1-\mathrm{H} 1 \mathrm{~A} \cdots \mathrm{O} 2$ & $0.95(3)$ & $1.67(3)$ & $2.552(2)$ & 153 \\
\hline
\end{tabular}

\section{Photoluminescent Properties of the Complex \\ Data acquisition in regards to excitation and radiation spectra for various modes such as luminescence, phosphorescence, and bioluminescence is available in modern photoluminescent spectroscopy. Acquiring the excitation spectrum, excitation chromator scans keeping a specific radiation wavelength constant while excitation wavelength is kept constant when radiation monochromator scans in obtaining a radiation spectrum.}

Eu(III) radiation usually consists of stripes at red spectral region. This ion corresponds to transitions from excited ${ }^{5} D_{0}$ of $4 f$ configuration to ${ }^{7} F_{j}(j=0$ to 6$)$ level. The most intense red emission line results from ${ }^{5} \mathrm{D}_{0} \rightarrow{ }^{7} \mathrm{~F}_{1}$ magnetic dipole transitions, ranging between 610 and $630 \mathrm{~nm}$ wavelength.

Excitation and radiation spectra of the complex, in its solid state, was recorded at room temperature with a scan interval of $\lambda$ ex:15 $\mathrm{nm} / \lambda \mathrm{em}: 15.0 \mathrm{~nm}$. Eu(III) complex was excited by UV light at $306 \mathrm{~nm}$. The emission band observed at $615 \mathrm{~nm}$ corresponds to ${ }^{5} \mathrm{D}_{0} \rightarrow{ }^{7} \mathrm{~F}_{2}$ electrical dipole transition (Figure 10).

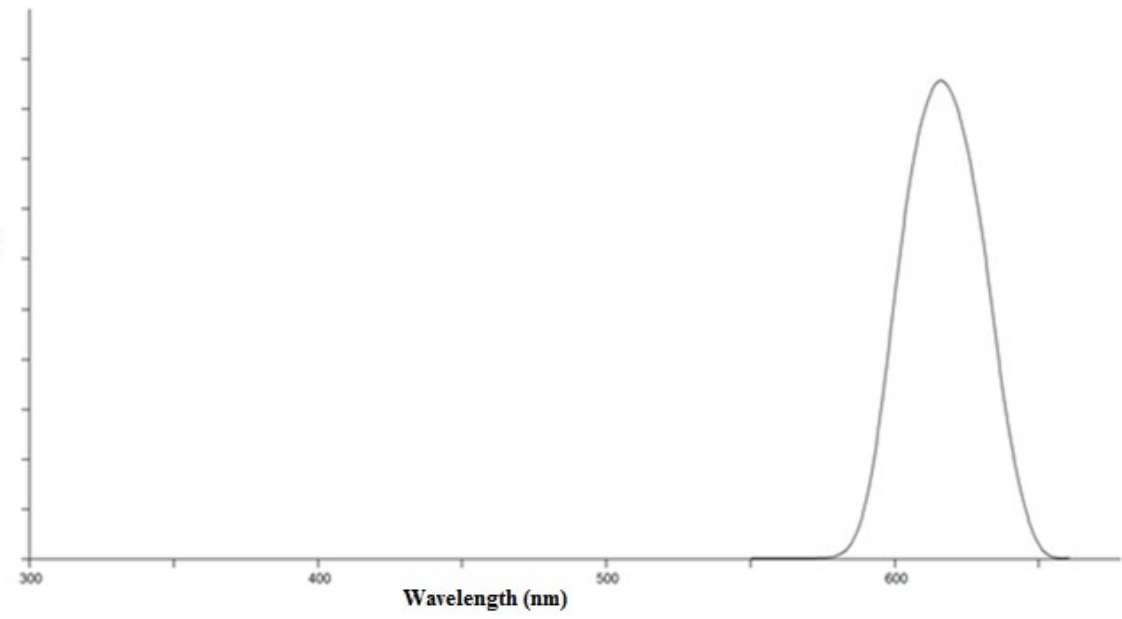

Figure 10: Emission spectrum of the complex $\left(\mathrm{H}_{2} \mathrm{O}, 1.0 \times 10^{-5} \mathrm{M}\right)$.

\section{CONCLUSION}

A novel $\beta$-diketone based ligand and its Eu(III) complex has been synthesized in pursuit of advancing a biolabel in techniques for labeling biomolecules in this study. $\mathrm{H}_{2} \mathrm{ODIT}$ and $\mathrm{H}_{2}$ CODIT ligands were elucidated by using ${ }^{13} \mathrm{C}$ NMR, ${ }^{1} \mathrm{H}-\mathrm{NMR}$, mass spectrometry and FTIR spectroscopic techniques. Furthermore, X-ray analysis of single crystal synthesis of $\mathrm{H}_{2}$ ODIT ligand was carried out. As a result, this ligand prefers enolic structure in the equlibrium of keto-enol tautomer. $\mathrm{H}_{2} \mathrm{CODIT}$ ligand was synthesized with $\mathrm{EuCl}_{3}$ complex, and luminescent analysis was carried out in order to investigate the viability of its biolabeling. 


\section{SUPPLEMENTARY DATA}

Crystallographic data for the structural analysis has been deposited with the Cambridge Crystallographic Data Centre, CCDC No. 1817092. Copies of this information may be obtained free of charge from the Director, CCDC, 12 Union Road, Cambridge CB2 1EZ, UK (fax: +44-1223-336033; e-mail: deposit@ccdc.cam.ac.uk or www: http://www.ccdc.cam.ac.uk).

\section{ACKNOWLEDGMENTS}

This study has been supported by TÜBİTAK BİDEB 2210-C Master's Scholarship Program for Priority Fields.

\section{REFERENCES}

1. Weissman SI. Intramolecular Energy Transfer The Fluorescence of Complexes of Europium. The Journal of Chemical Physics. 1942;10(4):214-7. <DOI>

2. Richardson FS. Terbium (III) and europium (III) ions as luminescent probes and stains for biomolecular systems. Chemical Reviews. $1982 ; 82(5): 541-52$

3. Hemmilä I. Fluoroimmunoassays and immunofluorometric assays. Clinical Chemistry. 1985;31(3):359-70. <DOI>

4. Gudgin Dickson EF, Pollak A, Diamandis EP. Ultrasensitive bioanalytical assays using timeresolved fluorescence detection. Pharmacology \& Therapeutics. 1995;66(2):207-35. <DOI>

5. Gudgin Dickson EF, Pollak A, Diamandis EP. Time-resolved detection of lanthanide luminescence for ultrasensitive bioanalytical assays. Journal of Photochemistry and Photobiology B: Biology. 1995;27(1):3-19. $<$ DOI $>$

6. Hemmilä I, Laitala V. Progress in Lanthanides as Luminescent Probes. J Fluoresc. 2005;15(4):529-42. <DOI>

7. Armelao L, Quici S, Barigelletti F, Accorsi G, Bottaro G, Cavazzini $M$, et al. Design of luminescent lanthanide complexes: From molecules to highly efficient photo-emitting materials. Coordination Chemistry Reviews. 2010;254(5-6):487-505. <DOI>

8. Melby L, Rose N, Abramson E, Caris J. Synthesis and fluorescence of some trivalent lanthanide complexes. Journal of the American Chemical Society. 1964;86(23):5117-25.

9. Choppin GR, Peterman DR. Applications of lanthanide luminescence spectroscopy to solution studies of coordination chemistry. Coordination Chemistry Reviews. 1998; 174(1):283-99. <DOI>

10. Andres J, Chauvin A. Luminescence. In: Atwood D, editor. The Rare Earth Elements: Fundamentals and Applications Lanthanides: Luminescence Applications. John Wiley and Sons; 2012. p. 135-52. ISBN: 978-1-11863263-5.

11. Binnemans K. Rare-Earth Beta-Diketonates. In: Gschneidner KA, editor. Handbook on the physics and chemistry of rare earths. 1 . ed. Amsterdam: Elsevier North Holland; 2005. p. 107-272. ISBN: 978-0-444-52028-9.

12. Yuan J, Matsumoto K. Synthesis of a New Tetradentate .BETA.-Diketonate-Europium Chelate That Can Be Covalently Bound to Proteins in Time-Resolved Fluorometry. Anal Sci. 1996;12(5):695-9. <DOI>

13. Hagan AK, Zuchner T. Lanthanide-based time-resolved luminescence immunoassays. Anal Bioanal Chem. 2011;400(9):2847-64. $\leq \mathrm{DOI}>$

14. Räsänen $M$, Takalo $H$, Rosenberg J, Mäkelä J, Haapakka K, Kankare J. Study on photophysical properties of Eu(III) complexes with aromatic $\beta$-diketones - Role of charge transfer states in the energy migration. Journal of Luminescence. 2014;146:211-7. <DOI>

15. Zhang $L$, Wang $Y, Y e Z$, Jin $D$, Yuan J. New Class of Tetradentate $\beta$-Diketonate-Europium Complexes That Can Be Covalently Bound to Proteins for Time-Gated Fluorometric Application. Bioconjugate Chem. 2012;23(6):1244-51. <DOI>

16. Siitari H, Hemmilä I, Soini E, Lövgren T, Koistinen $V$. Detection of hepatitis $B$ surface antigen using time-resolved fluoroimmunoassay. Nature. 1983;301(5897):258-60. <DOI>

17. Darwish IA. Immunoassay Methods and their Applications in Pharmaceutical Analysis: Basic Methodology and Recent Advances. Int J Biomed Sci. 2006;2(3):217-35. <URL> 
18. Yuan J, Matsumoto K. Synthesis of a new tetradentate $\beta$-diketonate-europium chelate and its application for time-resolved fluorimetry of albumin. Journal of Pharmaceutical and Biomedical Analysis. 1997;15(9-10):1397-403. $\leq \mathrm{DOI}>$

19. Wang G, Yuan J, Matsumoto K, Hu Z. Homogeneous Time-Resolved Fluorescence DNA Hybridization Assay by DNA-Mediated Formation of an EDTA-Eu(III)- $\beta$-Diketonate Ternary Complex. Analytical Biochemistry. 2001;299(2):169-72. <DOI>

20. Sheldrick GM. A short history of SHELX. Acta Crystallogr A Found Crystallogr. 2008;64(1):112-22. <DOI>

21. Sheldrick GM. Crystal structure refinement with SHELXL. Acta Crystallogr C Struct Chem. 2015;71(1):3-8. <DOI>

22. Anonymous. APEX2. Bruker AXS, Inc., Madison, Wisconsin, USA; 2013.

23. Macrae CF, Bruno IJ, Chisholm JA, Edgington PR, McCabe $P$, Pidcock $E$, et al. Mercury CSD 2.0 - new features for the visualization and investigation of crystal structures. J Appl Crystallogr. 2008;41(2):46670. $\leq \mathrm{DOI}>$

24. Farrugia $L$. WinGX and ORTEP for Windows: an update. J Appl Crystallogr. 2012;45(4):849-54. <DOI>
25. Erdik E. Organik kimyada spektroskopik yöntemler. Ankara: Gazi Büro Kitabevi; 2008. ISBN: 978-975-7373-04-9.

26. Bhise N, Al-Horaibi S, Gaikwad S, Rajbhoj A. Synthesis, Spectral Characterization, Antimicrobial, Anti-Inflammatory, Antioxidant, And Cyclic Voltammetric Studies Of $\beta$-Diketone And Its Metal Complexes. Rasayan J Chem. 2019;12(1):101-13. <DOI>

27. Yang C, Xu J, Ma J, Zhu D, Zhang Y, Liang $L$, et al. An efficient long fluorescence lifetime polymer-based sensor based on europium complex as chromophore for the specific detection of $\mathrm{F}-, \mathrm{CH} 3 \mathrm{COO}-$, and H2PO4-. Polym Chem. 2012;3(9):2640. <DOI>

28. Nakamoto K. Infrared and Raman spectra of inorganic and coordination compounds. 6th ed. Hoboken, N.J: Wiley; 2009. 23 p. ISBN: 978-0471-74493-1.

29. Charette J, Neirynck G, Teyssié Ph. Structural dependence of absorption spectra of $\beta$-diketone chelates. II. Ultraviolet 1 . J Phys Chem. 1961;65(5):735-9. <DOI>

30. Sultan R, Gadamsetti K, Swavey S. Synthesis, electrochemistry and spectroscopy of lanthanide(III) homodinuclear complexes bridged by polyazine ligands. Inorganica Chimica Acta. 2006;359(4):1233-8. <DOI> 